\title{
imperialismo e questão nacional em nelson werneck sodré ${ }^{\star}$ \\ imperialism and national question in nelson werneck sodré
}

\author{
Carlos Alberto Cordovano Vieira $\star \star \star$ \\ Instituto de Economia, Universidade Estadual de Campinas, Campinas, São Paulo, Brasil \\ Fábio Antonio de Campos $\star \star \star$ \\ Instituto de Economia, Universidade Estadual de Campinas, Campinas, São Paulo, Brasil
}

\section{RESUMO}

Entre o processo de Independência e o da Revolução Brasileira (1822-1964), o presente trabalho propõe discutir a questão nacional na obra de Nelson Werneck Sodré, a partir de sua investigação em torno dos momentos cruciais da formação histórica do Brasil. Para Sodré, a questão nacional nasce da consciência coletiva de parte da população, que assim vai se forjando como "povo", na luta contra as condições sociais deletérias impostas pela dominação imperialista. Como hipótese, propomos que tais marcos e seu tratamento pela obra de Sodré só podem ser devidamente compreendidos no quadro geral da crise do capitalismo em sua fase imperialista, desencadeada desde a Primeira Guerra Mundial e a Revolução Russa, tendo como uma de suas expressões as lutas de libertação nacional.

Palavras-chave: Nelson Werneck Sodré. Imperialismo. Revolução Brasileira. Questão nacional. Historiografia.

\begin{abstract}
This paper proposes to discuss the national question in Nelson Werneck Sodré's works on Brazilian history and its crucial moments between the Independence process and the revolutionary conjuncture in the decade of 1960 (1822-1964). In Sodré's perspective, national question emerges from "people" struggle against the deleterious conditions imposed by imperialist domination. Our hypothesis is that these crucial moments can only be understood in the contest of capitalist's crisis in its imperialist period, since the First World War and the Russian Revolution, considering national and anticolonial struggles as one of its expressions.
\end{abstract}

Keywords: Nelson Werneck Sodré. Imperialism. Brazilian Revolution. National question. Historiography.

* Submetido: 18 de junho de 2018; aceito: 13 de janeiro de 2019.

$\star \star$ Professor do Instituto de Economia da Universidade Estadual de Campinas. Doutor em Desenvolvimento Econômico pela Universidade Estadual de Campinas. E-mail: cordovanovieira@yahoo.com.br

$\star \star \star$ Professor do Instituto de Economia da Universidade Estadual de Campinas. Doutor em Desenvolvimento Econômico pela Universidade Estadual de Campinas. E-mail: fcampos6@yahoo.com.br 


\section{Introdução}

No momento atual, em que as principais conjunturas revolucionárias latino-americanas se converteram em contrarrevoluções e a transnacionalização do capitalismo reconfigura o estatuto do Estado nacional, a releitura de uma obra clássica torna-se fundamental ${ }^{1}$. Ao buscar as dimensões mais estruturais de nossa formação nacional nos quadros do imperialismo, a obra de Nelson Werneck Sodré se projeta para além de seu próprio contexto histórico, constituindo-se como uma chave para apreender as contradições de nossos dias e suas raízes históricas mais profundas.

Recentemente inúmeras contribuições sobre a obra de Sodré surgiram para se antepor a certas visões estigmatizantes que lhe identificavam como mero ideólogo do PCB (Partido Comunista Brasileiro), e para preencher o vácuo da ausência de estudos aprofundados de sua vasta obra no mesmo nível que de outros grandes intérpretes brasileiros. Nesse sentido, destacamos a pesquisa de Cunha $(2002,2006)$, que buscou a gênese da formação do autor ainda nas casernas, ou de Netto (2011), que mobilizou uma leitura sob o prisma da crítica literária e da trajetória intricada de vida e obra do autor, bem como os tratamentos historiográficos específicos que aprofundaram o debate da formação histórica brasileira, tais como Silva $(2001,2008)$ eVieira (2008). Embora alguns trabalhos tenham avançado na investigação da relação entre imperialismo e questão nacional em Sodré, de modo a derivar a anatomia da Revolução Brasileira em seu legado, como mostraram, particularmente, Toledo (2001), Oliveira Filho (2006) e Segato (2006), acreditamos que seria necessário desenvolver com maior precisão a conexão entre o condicionante externo que define revolução e contrarrevolução na matriz marxiana e a sua assimilação interna nas periferias de origem colonial como o Brasil à luz da questão nacional ${ }^{2}$.

1 Sobre a contextualização atual da formação econômica brasileira e seus dilemas, ver Campos (2018).

2 Conscientes das enormes polêmicas em relação ao nacionalismo no marxismo, não temos a pretensão neste trabalho de fazer uma análise exaustiva sobre as produções clássicas de tal tema até chegar ao nosso objeto de investigação que é Sodré. Para uma abordagem mais ampla desse universo, ver Hobsbawm (1990), Löwy (2000) e Pinsky (1980). 
O presente trabalho propõe discutir a questão nacional na obra de Nelson Werneck Sodré a partir de sua investigação em torno dos momentos cruciais da formação histórica do Brasil, entre o processo de Independência e da Revolução Brasileira (1822-1964). Para tanto, pretendemos examinar as articulações entre as dimensões universal e particular, em especial, a apropriação do materialismo histórico pelo autor, a partir de certas categorias marxianas, e sua concreção no estudo de uma formação específica, de origem colonial, e, posteriormente, subordinada ao imperialismo. Para Sodré (1962,1967), a questão nacional nasceria da consciência coletiva de parte da população, que assim vai se forjando como "povo", na luta contra as condições sociais deletérias impostas pela dominação imperialista.

Ao lado dos intérpretes clássicos de nosso país, temos por hipótese que Sodré observou um movimento histórico ascensional da colônia à nação, do subdesenvolvimento ao desenvolvimento, da escravidão à emancipação, da opressão à democracia, do colonialismo e do imperialismo à Revolução Brasileira; tudo isso inscrito numa quadra histórica também ascensional que veio, senão da Revolução Francesa, certamente da Revolução Russa e da dinâmica revolução/contrarrevolução que se instaurou a partir da crise do imperialismo. Mais do que isso, no ocaso dessa época, esses intérpretes ao lado de Sodré viram, não sem certa perplexidade, a vitória da contrarrevolução, as tendências à reversão neocolonial e, enfim, a interrupção do processo de formação nacional, cuja essência revelou as raízes mais profundas, as dimensões mais estruturais da crise contemporânea. Para enfrentar tal problemática na obra de Sodré, além desta introdução, abordaremos no próximo item a transição da colônia à "economia dependente" entre 1808 e 1929. Em seguida, trataremos da concepção de Sodré entre imperialismo e revolução, entre 1930 e 1964, finalizando com algumas considerações.

\section{Da colônia à "economia dependente” (1808-1929)}

\subsection{Origem colonial e emancipação}

As tensões entre a dimensão conceitual, em que se caracteriza o "modo de produção" na colônia, e a da narrativa de nossa formação histórica, as 
tensões entre o "particular" e o "universal" na obra de Werneck Sodré, foram objeto de crítica em diversos trabalhos que não pretendemos retomar aqui.

Registre-se somente a hipótese de que, no delineamento do sentido da formação, operavam forças concernentes menos a especificidades dos referidos "modos de produção" coloniais que a nexos propriamente mercantis. Tomado o plano da narrativa, o movimento de cada núcleo de povoamento em diferentes momentos da história da colônia, a constituição, o crescimento e a crise de cada centro de produção da vida material, era dinamizado pelo mercado mundial, mais que por determinantes engendrados a partir da reprodução, digamos, "interna", das relações de produção vigentes. Dinâmica mercantil, que Caio Prado Jr. colocara no âmago do "sentido da colonização". Considere-se também que, posto que houvesse, por outro lado, sustentação empírica para a caracterização do mosaico de "modos de produção" (Sodré, 1997a; Cunha, 2002), a tensão entre o conceito e a história devia-se não a uma mera transposição mecânica de esquemas preestabelecidos - crítica recorrente ao historiador -, mas à reprodução de tendências teóricas disseminadas no materialismo histórico da época que, restringindo o conceito de "modo de produção" praticamente à dimensão das relações de produção, terminara por estreitar os conceitos de escravismo e capitalismo e estender, em compensação, o de feudalismo.Tal tendência não era estranha, por exemplo, ao debate historiográfico entre Maurice Dobb e Paul Sweezy, que como outros debatedores, ao cabo, referiam-se a "feudalismos" (Vieira, 2004, 2012). Assim formalmente definido o "modo de produção", toda a especificidade do concreto corria à margem do próprio conceito.

Nesta primeira parte do presente trabalho cumpre concentrar a observação no plano da narrativa proposta por Sodré para ressaltar um traço, para nós, fundamental no equacionamento do debate brasileiro, qual seja, a preservação, ao longo do tempo, de estruturas herdadas do passado colonial.

Para Sodré, o momento crucial no processo histórico de diferenciação da sociedade colonial residiu na formação da economia mineira durante o século XVIII. O crescimento da colônia, que passou, então, de 300.000 a 3.300.000 habitantes, foi uma expressão quantitativa de mudanças substanciais em sua conformação, que produziram reflexos no desenvolvimento de uma consciência nativista e, enfim, no acirramento da luta 
de classes. À diferença de Caio Prado Jr. (2000), que tomava, digamos, por circunstanciais as especificidades do negócio das minas, Sodré sublinhava - como fizera, aliás, Furtado (1975) -, em contraste com o açúcar, o caráter mais rudimentar da estrutura técnica da exploração do ouro de aluvião, e, pois, as exigências menos restritivas em termos de capitais e, pois, das escalas de produção, que correspondiam a uma maior dispersão da propriedade. Naturalmente, a centralidade da propriedade da terra como fundamento da estratificação, típica da sociedade do açúcar, dava lugar, nas minas, à concessão de licenças para minerar. Tal conformação e, sobre essa base, o próprio crescimento demográfico, combinados à natureza essencialmente monetizada da economia - em que o ouro funcionava ao mesmo tempo como moeda e mercadoria -, concorreram para o avanço da divisão do trabalho e para os primeiros esboços de entrelaçamentos mais orgânicos no nível do "mercado interno".

Essas mudanças correspondiam a uma transformação no regime escravista colonial. Com as mudanças quantitativas expressas no aumento do tráfico marítimo e do comércio local de escravos a preços sempre mais elevados, a economia mineira engendrou, entre os estratos tradicionais da vida colonial, uma camada média vinculada à expansão do trabalho livre. Tudo isso concorria para um agravamento das tensões concernentes à exploração do butim colonial. Tal tensão se radicalizava tanto mais porquanto o vetor da exploração deixava de ser o mecanismo, de certa forma mais velado, do controle das linhas de financiamento e comércio pelo monopólio do capital mercantil, para ser - dada a natureza do negócio do ouro - um regime progressivamente violento de controle da produção e de taxação direta. A clausura do Distrito Diamantino, espécie de presídio, constitui um exemplo paradigmático. $\mathrm{Na}$ economia açucareira, os espaços de controle das classes dominantes metropolitanas e coloniais eram delimitados por uma separação relativamente bem definida entre as esferas da circulação e da produção. $\mathrm{O}$ monopólio metropolitano, com o concurso do capital mercantil holandês, permanecia restrito à circulação, operando nas linhas de financiamento e comercialização, ao passo que ao senhoriato local cumpria comandar a produção escravista. $\mathrm{Na}$ economia mineira, a metrópole invadiu a órbita da produção, o peso dos tributos entre suas expressões. Abriu-se, pois, um conflito mais explícito ${ }^{3}$.

3 “A mudança singular que a mineração opera é a de tornar evidente o mecanismo de 
Trata-se de uma mudança profunda, de consequências políticas cruciais no nível dos realinhamentos da luta de classes. Para Sodré, se, na sociedade do açúcar, os proprietários de escravos operavam, de certa forma, como representantes locais das classes dominantes metropolitanas, não obstante o regime do exclusivo nas minas, a diferenciação do espaço colonial em tensão com os desígnios da exploração produzia uma fratura entre os estratos dominantes. Nesse palco, florescerão os primeiros traços de uma consciência nacional, cujos desdobramentos resultarão nos conflitos políticos mineiros e, mais à frente, na própria emancipação.

Na obra de Sodré, Minas Gerais, ainda no período colonial, é que revelaria os primeiros esboços do choque entre as classes dominantes locais e a dominação colonialista - mais tarde, especificamente, "imperialista" -, bem como, e não por acaso, o nascimento de uma camada média que jogará sempre, para Sodré, um papel político fundamental. Trata-se dos embriões de elementos fundamentais na construção de sua teoria da Revolução Brasileira ${ }^{4}$.

Em Razões da Independência, Sodré (1978a) circunscreveu com mais rigor a tensão entre a diferenciação da colônia e os limites da condição colonial no quadro geral da crise que consumia o movimento de transição do feudalismo ao capitalismo:nesse momento, as tensões confluem para o processo de emancipação.

Posto que o desenvolvimento do capital mercantil, fundado no sistema colonial, engendrasse, mesmo que em limites estreitos, a diferenciação das formações coloniais, a ruptura que consuma a transição se exprime também, naturalmente, num agravamento das tensões entre as

transferência da renda para o exterior, de desvendá-lo. Isso contribuirá para expandir a consciência da exploração colonial. O regime de monopólio de comércio, e sua consequência natural - a clausura - atinge dimensões larguíssimas e profundas com a mineração. [...] O regime de monopólio comercial, numa etapa muito mais avançada do desenvolvimento da colônia, faz aflorar e aprofunda a contradição entre a classe dominante colonial e a classe dominante metropolitana." (Sodré, 1975, p. 34-35)

4 "A uma nova situação econômica corresponde sempre uma nova estrutura de classes. No caso, os efeitos foram o aparecimento de uma camada média e a ampliação da área de trabalho livre. A sociedade mineradora é diferente da sociedade açucareira. A taxação espoliativa, a cisão de interesses entre a classe dominante na Colônia e a Coroa, o caráter brutal que assume o regime de monopólio comercial levam, finalmente, ao quadro da Inconfidência Mineira, que caracteriza o declínio minerador e define a referida cisão. Da Inconfidência à independência decorrem, por isso mesmo, pouco mais de três décadas." (Sodré, 1976, p. 139-140) 
classes dominantes coloniais e metropolitanas. Nesse quadro de crise estrutural, a diferenciação da economia mineira no século XVIII, que entrava em sinergia com a constituição do capitalismo na Inglaterra por meio do franqueamento da economia portuguesa a suas manufaturas, precipitava também conflitos emancipatórios. A Revolução Industrial, ao criar as forças produtivas correspondentes às novas relações de produção fundadas no trabalho "livre", deslocou o predomínio do capital mercantil em favor das formas mais plenamente desenvolvidas do capital. A consolidação do capitalismo britânico colocou em causa a necessidade de expansão dos mercados que se chocava contra os velhos monopólios mercantis.

Os conflitos que se estendiam nos desdobramentos da revolução burguesa, entre os quais a colisão definitiva entre colônias e metrópoles, eram episódios do confronto do novo contra o velho modo de produção. A luta que envolveu as pretensões da Inglaterra pelo deslocamento dos entrepostos ibéricos para a conquista dos mercados americanos e, de outro lado, a resistência das metrópoles e o emaranhado de conflitos internos ao mundo colonial eram os episódios derradeiros do longo movimento de transição. O ponto crucial, portanto, consiste na emancipação como passagem da subordinação ao sistema colonial de caráter feudal ibérico ao capitalismo britânico em expansão. Nesse processo, não eram indiferentes as posições relativas das monarquias nos conflitos "geopolíticos" que jogavam seu papel na forma da transição - nas colônias espanholas, por meio de um processo revolucionário de ruptura com a metrópole, em que a penetração britânica era mais dificil; na colônia portuguesa, por meio da introjeção da metrópole no espaço colonial, por meio do que a posição privilegiada da Inglaterra se fazia de forma direta (Sodré, 1978a; Novais, 1995) ${ }^{5}$.

5 “A consolidação da classe senhorial no poder [...] responde pelo largo período de lento desenvolvimento, quando as características fundamentais do que havia de essencial no sistema colonial persistiram atuando. Passávamos da dependência política de metrópole decadente para a dependência econômica e financeira de metrópole próspera. Realizávamos um avanço, sem a menor dúvida. Mas o processo da independência ficava em meio, por força das condições dominantes no mundo e no Brasil."' (Sodré, 1978a, p. 261) 


\subsection{Formação nacional e herança colonial}

O que se segue é a preservação, no novo quadro, de traços essenciais do passado colonial. Particularmente, a "externalidade da acumulação".

Com efeito, porquanto a emancipação das colônias correspondesse a projeções do desencadeamento da revolução burguesa, o processo, no conjunto, não produziu, na América Latina, rupturas revolucionárias com o mesmo conteúdo. Para Sodré, se a emancipação na América Latina não redundou num processo de revoluções burguesas, isso se deve, essencialmente, ao caráter colonial dessas formações - e, nesse caso, o desfecho revolucionário tardio na Guerra Civil nos Estados Unidos, última experiência de ruptura democrático-burguesa, viria atestar a especificidade de uma colônia, digamos, "de povoamento". Enfim, esse traço de heterocronia marcará toda a formação histórica do Brasil. No momento em que as condições estiverem consolidadas para a Revolução Brasileira, seu caráter, como veremos, será também transfigurado por força das condições históricas gerais do capitalismo em crise do século XX. No século XIX, as posições da burguesia britânica e dos proprietários locais confluíram quanto aos limites da emancipação, o que fez preservar os traços coloniais. A manutenção da estrutura primário-exportadora, posto que cristalizava o poder senhorial local, era também funcional ao capitalismo em consolidação, escravidão à parte. Este é o sentido do desfecho do processo nas revoltas do período regencial (Sodré, 1939).

Tal linha de continuidade se preservou, no entanto, com especificidades dadas por uma nova quadra histórica: a passagem do predomínio do capital mercantil às formas mais desenvolvidas do capital, sob o modo de produção capitalista já constituído; a passagem do domínio das classes metropolitanas "feudais" ao domínio da burguesia em nível mundial; de uma sociedade essencialmente rural a outra, no centro europeu, em progressivo processo de urbanização e industrialização, no limiar de uma transição demográfica.

Tudo isso marcaria um novo tipo de subordinação do polo colonial ao centro que Sodré (1976), em Formação histórica do Brasil, caracterizou nos termos de uma condição de "dependência"”. A nova divisão do

\footnotetext{
6 "Conceituamos como economia dependente aquela em que se operam mudanças
} 
trabalho promove uma organicidade maior entre os polos da economia mundial, baseada não mais nos parâmetros ecológicos, que pautavam uma espécie de especialização absoluta, mas em condicionantes da concorrência capitalista, que levam a uma especialização relativa, dada pela equação das "vantagens comparativas" - a subordinação política dá lugar à "dependência" econômica. Mantido o invólucro colonial, a "economia dependente" terá, no entanto, nesse novo quadro, dinamismos que não existiam na economia colonial do passado. A reprodução da velha estrutura colonial nos quadros de um novo modo de produção, o capitalismo plenamente constituído, permitia certa expansão, mesmo que limitada, do mercado interno. Mais que isso, removido o exclusivo metropolitano, gestavam-se condições para uma acumulação capitalista local, ainda que debilitada pelas vicissitudes de seus traços coloniais.

Visto em seu conjunto, o desenvolvimento pleno da "economia dependente" viria somente em fins do século XIX, quando a dominação a partir do centro do capitalismo mundial tomasse a forma de uma dominação propriamente imperialista.

Dos traços constitutivos dessa nova etapa, destaca-se a tendência à sobreposição da circulação de capitais à circulação de mercadorias (Lenin, 1979). Portanto, no último quartel do século XIX, a "economia dependente" era marcada pela presença dos capitais estrangeiros, especialmente britânicos, com o que, sobre o balanço de pagamentos, além da deterioração dos termos de troca e dos serviços do endividamento, pesavam as remessas de lucros. Para delinear os nexos dessa nova articulação, há que considerar que os dinamismos da "economia dependente" fizeram avançar a diferenciação e levaram a transformações, muito embora localizadas, profundas a partir de meados do século XIX. Essencialmente, entre o fim do tráfico e a Abolição, avançava, no Centro-Sul, a expansão de relações de produção já propriamente capitalistas e, no bojo da economia cafeeira do Sudeste, os primeiros ensaios de uma

qualitativas suficientes para distingui-la da economia colonial; as mudanças mais significativas, no caso, consistem na existência e desenvolvimento, lento ou não, do mercado interno, e na gestação de pré-condições para a acumulação capitalista, decorrentes do fato de que parte da renda gerada se conservava no interior [...]. A rigor, no entanto, a estrutura dependente, e a economia a que corresponde, guarda muito da estrutura colonial e da economia a que esta corresponde; particularmente no que diz respeito à característica essencial: o fluxo da renda volta-se ainda, em grande parte, para o exterior." (Sodré, 1975, p. 36) 
indústria. Ilustra esse movimento o crescimento demográfico que faz saltar a população de 4 milhões para 15 milhões de habitantes. Mas esse núcleo dinâmico avançava em meio a um emaranhado de formas denominadas "pré-capitalistas", dominantes no conjunto da formação social brasileira. Para Sodré, essas formas, os tão controversos "resíduos feudais", constituíam obstáculos ao pleno desenvolvimento de um capitalismo em bases nacionais, condicionando diversos fluxos de transferências do excedente, de renda, em prejuízo das camadas médias e mesmo de uma burguesia nascente.

A natureza colonial da formação brasileira permanecia preservada no caráter de "economia de exportação". Em que pesem as críticas explícitas ao tratamento cepalino do problema e o léxico próprio do marxismo, devidamente considerada, a leitura de Sodré não difere, a rigor, por exemplo, de proposições paradigmáticas como as de Celso Furtado ${ }^{7}$.

No curso do século XIX, entre a crise dos primeiros decênios e a consolidação do café, a concentração da pauta de exportações nos produtos tradicionais se acentuou, o café predominando progressivamente sobre o açúcar, a erva-mate, o fumo, o algodão, a borracha, os couros e as peles. De outro lado, a diversificação da pauta de importações, constituída basicamente por produtos de consumo generalizado como vestuários, calçados, alimentos e utensílios em geral - traço típico de economias coloniais -, permaneceu, embora registre, no bojo da expansão cafeeira, uma pequena elevação da importação de produtos como carvão ou máquinas, o que revelava a presença de alguma indústria insipiente. Com efeito, a expansão do café produziu, pelo menos desde o decênio de 1860, uma inversão da tendência crônica ao deficit na balança comercial e, nesse quadro, a dinâmica do endividamento ganhou novos contornos. Se num primeiro momento o endividamento respondia à necessidade do financiamento de deficit comerciais, depois disso viria fazer frente às pressões sobre o balanço de pagamentos gerados pelo serviço das dívidas precedentes, bem como pelas remessas de lucros dos novos investimentos estrangeiros que se elevavam na nova etapa do capitalismo. Numa economia dessa natureza, não admira que os princípios

7 É sintomático que Octávio Rodriguez tivesse sugerido uma proximidade entre o paradigma cepalino e as teses do Partido Comunista. 
supostamente universais do padrão-ouro fossem subvertidos na prática - como de resto, o conjunto dos preceitos liberais, numa economia de origem colonial e escravista -; e, com efeito, as desvalorizações monetárias foram constantes no curso do século, mesmo nos períodos de superavit na balança comercial - superavit, como vimos, contrarrestados, em parte, pelo peso do serviço da dívida. Dadas as discrepâncias entre as elasticidades da produção primária e as da manufatureira - esta mais elástica que aquela -, as conjunturas de crise cíclica produziam tendências à deterioração dos termos de troca, respondidas com desvalorizações cambiais. Como mostrara Furtado (1975), tratava-se de um mecanismo de "socialização" dos prejuízos. Além disso, o encaminhamento dos problemas fiscais operava também como mecanismo de transferências. A partir de 1844, com Alves Branco, passada a vigência das tarifas preferenciais, a concentração da tributação nas importações, porquanto preservasse as classes exportadoras, promovia transferências de renda do conjunto da população à grande propriedade; e, sempre que o mecanismo cambial corroesse os tributos, cobrados a taxas fixas de câmbio, o governo recorria às emissões que redundavam, por sua vez considerados os seus efeitos sobre os preços relativos, numa espécie de tributação inflacionária. O quadro se agravava porquanto a defesa da moeda, nos termos do padrão-ouro, levasse à escalada dos empréstimos, cujos serviços eram financiados por esse mesmo sistema tributário regressivo.

Tais os nexos entre as bases precárias do balanço de pagamentos, do sistema monetário, do orçamento público e do circuito do endividamento; cada peça funcional a uma complexa engrenagem de espoliação que fazia transferir a renda da economia colonial ao capital estrangeiro, ao núcleo imperialista, e, internamente, do conjunto do povo às classes dominantes locais - particularmente, de uma insipiente "burguesia" ao latifúndio exportador. Estes eram, para Sodré, os limites ao pleno desenvolvimento do capitalismo em bases nacionais pela preservação do caráter essencialmente colonial da "economia dependente".

8 "Estabelece-se, assim, a associação profunda que ainda hoje existe, sob condições diversas das que antes imperavam, entre empréstimos externos, déficits orçamentários, déficits de balança de comércio exterior, investimentos externos, mecanismo de câmbio e emissões, gerando a aparente complexidade que disfarça uma espoliação continuada da economia nacional. Tudo isso ocorre e se processa numa estrutura colonial de produção. Na medida em que essa estrutura se modifica, surgem resis-- 
No exame da dinâmica da luta de classes que atravessa esse movimento secular, da emancipação à liquidação da escravidão e do Império, Sodré propõe a mediação que parte da seguinte pergunta: "Quem é o povo no Brasil?”. Dado que a constituição da sociedade de classes ponha a distinção entre povo e população e, portanto, o conceito de "povo", sem se reduzir a determinismos econômicos, seja sempre intimamente ligado à dimensão da estrutura de classes; e, sendo essa mesma estrutura de classes uma realidade em permanente movimento em virtude de particularidades históricas e geográficas, "povo" encerra uma determinada historicidade.

Para Sodré, "em todas as situações, povo é o conjunto das classes, camadas e grupos sociais empenhados na solução objetiva das tarefas do desenvolvimento progressista e revolucionário na área em que vive" (Sodré, 1967, p. 197). Entre a emancipação e a Abolição, como vimos, a sociedade brasileira passou por um profundo processo de diferenciação que foi tornando mais complexa a caracterização do "povo" e a dinâmica da luta de classes. Desde meados do século XVIII, a atividade mineradora, como vimos, ensejou o crescimento de uma camada média de pequenos proprietários, comerciantes, funcionários, militares, clérigos e intelectuais, entre o estrato dos senhores, grandes proprietários, e os escravos e servos. De outro lado, naquela quadra histórica, o regime de monopólio colocava o estrato dos grandes proprietários em linha com as "tarefas do desenvolvimento progressista", a emancipação. Assim, no momento da ruptura, todos são o "povo": a camada média, radicalizada; o estrato superior, também favorável, embora hesitante diante dos riscos de perder o controle do processo; e os escravos e servos, malformados propriamente como "povo", cumprindo um papel relativamente passivo, à exceção dos episódios de radicalização no período regencial.

O quadro muda com os desenvolvimentos do século XIX. O avanço do capitalismo, com o crescimento das cidades, das estruturas do Estado, com uma expansão do mercado interno e com os primeiros esboços da indústria, produziu o desenvolvimento da divisão do trabalho e, como corolário, um aumento e diversificação das camadas médias. Para Sodré, nessa quadra é possível falar, com mais rigor, de uma "classe média", de uma "pequena burguesia”.Aliás, em Sodré (1967), este é um dos pontos

tências, os antagonismos claríssimos, que desvendam o caráter daquela estrutura e demandam a sua modificação." (Sodré, 1976, p. 265-266) 
cruciais na História da burguesia brasileira: no Brasil, uma pequena burguesia precedeu a grande e operou como vanguarda da mudança social. Também os estratos superiores se tornam mais diversos com as mudanças ocorridas nas relações de produção. A corrosão da escravidão, desde o fim do tráfico, e a expansão das áreas de servidão e de salariato colocaram em choque, entre si, proprietários ligados às velhas e novas formas de produção. Com isso, uma burguesia nascente se destaca dos estratos dominantes, outrora homogêneos, para compor, com as camadas médias e a massa passiva dos trabalhadores, o "povo". Vale dizer: na ruptura da República, a classe dominante ligada ao chamado latifúndio "feudal” ou "semifeudal" e as últimas resistências escravistas estão excluídas, segundo essa classificação, do "povo". Mas, posteriormente, conforme a burguesia proprietária consolidava o controle do processo e estabelecia os limites da mudança social, ela mesma promoveu a rearticulação do velho latifúndio ao estrato dominante em prejuízo das camadas médias e dos trabalhadores. Nos conflitos da República e, pois, da Revolução Brasileira, o "povo" será outro.

\section{Imperialismo e revolução (1930-1964)}

A crise do imperialismo perfilaria um feixe de possibilidades para a periferia alforriar-se do domínio externo, enraizado desde o antigo sistema colonial até o período de rivalidade intercapitalista que culminaria com a Primeira Guerra Mundial. Na formação econômica brasileira, em particular, tal contexto radicalizaria o choque entre o desenvolvimento industrial e a resiliência da economia agroexportadora, em meio a um processo de proletarização e de consolidação de uma vanguarda nacionalista representada pela pequena burguesia que se antagonizava aos interesses dos latifundiários e do imperialismo. Foi com base nessa interpretação histórica que Sodré (1967,1976,1997a) delimitou a gênese da revolução democrática burguesa no Brasil. Para tanto, sua reflexão se definiu pelas seguintes questões:

1) a compreensão de como a dinâmica universal do capitalismo penetrava na sociedade brasileira cristalizando um padrão de dominação imperialista; 
2) o avanço nas forças produtivas que se refletia nas diferentes estratégias de desenvolvimento capitalista de cada governo brasileiro;

3) a conjunção das relações sociais de produção que compunha a dinâmica da luta de classes nesse período.

\subsection{Dinâmica universal do capitalismo}

O sentido da Revolução Brasileira em Sodré tinha como eixo a maturação do imperialismo na forma de crise capitalista e sua negação com a Revolução Russa. O autor mostrou que nossa identidade revolucionária guardava relação direta com essa transformação na história mundial, e não com o processo de revoluções burguesas dos capitalismos originários, assim como os da Segunda Revolução Industrial. Desse modo, a Revolução Russa abriria um novo tempo histórico, cujas implicações diluvianas à ordem imperialista se projetavam sobre a periferia, ampliando tensões só solucionadas em rupturas coloniais revolucionárias.

Podemos observar na obra de Sodré que a revolução burguesa no Brasil se desenvolveria justamente quando intensificava a crise do modelo revolucionário burguês clássico por conta do imperialismo, marcando uma nítida decomposição entre superestrutura e infraestrutura conforme determinados padrões de desenvolvimento capitalistas desiguais e combinados, numa típica relação de "heterocronia" (Sodré, 1997a). Em outras palavras, o desenvolvimento do capitalismo na periferia era contemporâneo ao da crise capitalista no centro, visto que o ciclo revolucionário burguês em economias de origem colonial seria correlato não às revoluções burguesas clássicas ou prussianas, mas à revolução socialista. Portanto, a condição de dependência em relação às potências imperialistas - e não de concorrência - condicionaria um ciclo revolucionário burguês caracterizado pela descolonização ${ }^{9}$. Nesse

9 Sodré desenvolveu tal proposição nos seguintes termos: "o desenvolvimento capitalista brasileiro é contemporâneo do declínio capitalista em escala mundial. Quando aquele atinge o nível em que define plenamente suas linhas, este atravessa a sua fase de crise geral. Os surtos capitalistas atrasados, isto é, os que se processaram mais tarde, no tempo - o da Alemanha, o do Japão -, guardam com os que iniciaram mais cedo uma relação de concorrência, por vezes belicosa; os que avançaram na fase de declínio dor regime em escala mundial guardam com os que se iniciaram cedo 
sentido, as reformas de conteúdo burguês a ele concernentes faziam parte de uma mesma fratura exposta pela crise do capitalismo central e pela revolução mundial, em que não haveria, segundo nosso autor, "muralhas" entre reforma e revolução a ser introduzidas nas periferias do sistema (Sodré, 1967) ${ }^{10}$.

O modelo soviético e o enraizamento das alternativas ao modo de produção capitalista exacerbariam as lutas de classe no mundo, inspirando inúmeros movimentos libertários nas economias periféricas. Apoiando-se em autores influenciados por Lenin, como Rosental (1959) e Nikitin (1967), Sodré (1968a) apreendeu como o capitalismo de livre-comércio se converteu historicamente em seu oposto, capital monopolista; e como dessa ordem nasceu a lei do desenvolvimento desigual do imperialismo, permitindo armar o proletariado com um diagnóstico certeiro da dominação do capital financeiro e suas consequências. Dessa teoria resultou também a reflexão do autor sobre o desenvolvimento político desigual, cujas contradições de classes se colocariam de formas distintas em cada região e conforme sua especificidade histórica, sendo que a decisão revolucionária dos proletariados, e sua capacidade de arrastar o campesinato consigo, obedeceriam a uma lógica intrínseca às especificidades de cada país. Descartava-se, assim, a teoria da revolução socialista simultânea e combinada a partir das economias centrais.

Segundo Nikitin (1967), a própria questão nacional na periferia não poderia ser compreendida sem o impacto da Primeira Guerra Mundial e da Revolução Russa nos povos dominados pelo imperialismo. A industrialização que germinava em alguns espaços periféricos como reação à crise imperialista não guardava relação com os efeitos diretos

uma relação de dependência. As contradições, num e noutro caso, são de ordem diferente: as primeiras, como se constata pela história contemporânea, desembocam nas guerras; as últimas, nos movimentos de libertação nacional, em que, no entanto, o regime é posto em causa, na sua essência" (Sodré, 1975, p. 58).

10 "Qual o fim das reformas [de base], realmente? Vitoriosas, corresponderiam a liquidar a dominação imperialista em nossa economia, a liquidar o poder dos latifundiários como classe, à ampliação da base democrática do poder. Programa modesto? Não, - programa gigantesco. Mas, evidentemente, programa não socialista, programa desenvolvido dentro dos marcos capitalistas da sociedade brasileira. Levando entretanto a substancial alteração na disposição das forças sociais e políticas do País [...]. O que nossos pretensos ultrarrevolucionários não sabiam, o imperialismo sabia: que as reformas tinham sentido revolucionário, que não se tratava de simples reformismo." (Sodré, 1978b, p. 231) 
do capital monopolista, mas um traço progressista das economias subdesenvolvidas para tornarem-se menos reféns do seu domínio. Articulada às condições mínimas de reprodução material dos povos de origem colonial, a luta pela emancipação nacional engendraria as condições históricas de descolonização via revoluções democráticas burguesas ou socialistas. As lutas pela emancipação nacional tenderiam a aglutinar proletários, camponeses e burguesias nacionais contra o imperialismo, sedimentando experiências concretas como as da China, da Índia, da Indonésia, da Birmânia, do Ceilão, de Cuba, da Coreia e doVietnã. Para Sodré (1968b) seria, desse modo, fundamental estabelecer um elo determinado entre o universal e a questão nacional nos termos de Lenin (1980) e seus seguidores, cuja tarefa essencial da luta de classes seria estudar, investigar e analisar cada particularidade histórica, em que cada nação enfrentaria internamente a correlação de forças entre o avanço da revolução nacional e o ataque contrarrevolucionário imperialista.

Da mesma forma que o imperialismo estava acossado por um vivo processo revolucionário mundial difundido pelo socialismo russo, encarnava, segundo a visão de Sodré, uma dimensão contrarrevolucionária internacional, cuja "natureza moribunda" se expressava por duas guerras mundiais intermediadas pela Crise de 1929. Tendo como matriz histórica uma plêiade de contradições do capital monopolista que fecundava descolonização e socialismo, o resultado da crise do capitalismo constituía a prova de que as potências imperialistas não tinham nada a oferecer, visto que o imperialismo sepultara a promessa civilizatória oriunda da revolução clássica burguesa. Deixar a América Latina dependente de tal dominação seria o mesmo que mantê-la alijada do componente nacional e democrático, justamente a base da autodeterminação dos povos. Daí ter que recorrer à força, inclusive militar, para iniciar revolucionariamente sua descolonização.

\subsection{Desenvolvimento das forças produtivas e relações sociais no Brasil}

Com base nessas premissas foi que Sodré (1978b, 1997a) definiu o surgimento da Revolução Brasileira, tendo como parâmetro dois ângulos de análise: a especificidade do desenvolvimento das forças produtivas e as mutações nas relações sociais de produção. No que se refere ao pri- 
meiro enfoque, o autor concebeu o avanço da industrialização na década de 1930 como resultado progressista proveniente da crise do imperialismo, assim como da intervenção do Estado em determinadas estratégias de desenvolvimento capitalista que se inscreviam na Revolução de 1930 e na "época de Vargas" (1930-1945, 1951-1954). Ainda que não significasse uma ruptura com o imperialismo nem com o passado feudal marcado pelo domínio do latifúndio, o período que se abria seria um importante passo para o avanço das forças produtivas (Sodré, 1967, 1997a).

O autor dividiu o processo de industrialização em três etapas (Sodré, 1975). Na primeira, a origem da indústria no país (1850-1930) esteve marcada pela introdução no mercado interno das mercadorias do imperialismo, impondo preços e condições submetidos às tarifas de alfândegas. Não obstante, mesmo na época em que se procurava defender a "vocação agrícola", a indústria tentava satisfazer o mercado interno, exigindo proteção. Em uma segunda etapa, que coincidia com a "época de Vargas" (1930-1945, 1951-1954), ainda que o imperialismo passasse a produzir à sombra das tarifas, a indústria brasileira usufruía do protecionismo e do desenvolvimento das relações capitalistas, disputando diretamente com os monopólios estrangeiros. Momento distinto marcou o início da terceira etapa, cuja implantação da indústria pesada na segunda metade da década de 1950, e seu avanço pelas décadas seguintes, eram condicionados diretamente pelo imperialismo. Segundo Sodré, foi justamente quando se abriram as oportunidades internas para uma maior autonomia econômica que os monopólios estrangeiros, ligados aos setores de bens de capital e de consumo duráveis, fincaram sua estrutura imperialista no mercado interno, controlando o dinamismo da economia brasileira.

Fica nítida aqui a conexão que Sodré conceberia das forças produtivas com determinados estilos capitalistas de desenvolvimento, denotando uma complexa articulação entre a evolução da infraestrutura e as descontinuidades da superestrutura, cujos arranjos de poderes políticos e militares poderiam desencadear conciliação ou subordinação ao imperialismo. Em Vargas, embora tivesse sido o momento que o Brasil vislumbrou uma certa independência econômica ante os interesses imperialistas, o caminho trilhado pelas linhas de menor resistência se mostrou de difícil conciliação entre Estado, burguesia brasileira e forças 
externas. Na verdade, ao tentar regular o acesso do imperialismo na economia brasileira, Getúlio Vargas, na abordagem de Sodré (1976, 1997a), acabou por fracassar como governo.

A quadra histórica que se abriu em seguida foi totalmente distinta, porquanto o período Kubitschek (1956-1961), antecedido por Café Filho (1954-1955), e radicalizado após o Golpe de 1964, apresentou uma ruptura na estratégia varguista de desenvolvimento autônomo segundo o autor.A forma pela qual o Plano de Metas servia como instrumentalização estatal para cessão de benefícios aos monopólios internacionais e a associação dependente de parte da burguesia brasileira definiria, na visão de Sodré (1975,1997a), o padrão de subordinação ao imperialismo nas décadas seguintes, de tal modo que na longa duração seria possível delimitar com exatidão o período Vargas e as implicações futuras de sua queda. De acordo com Sodré (1997a), até o segundo governo Vargas, o país tinha um capitalismo monopolista de Estado que impulsionava o desenvolvimento das forças produtivas, além de possuir elementos de estímulo institucional à dinamização industrial, uma vez que a área estatal da economia funcionava como componente nacional dessa mesma economia via, por exemplo, Companhia Siderúrgica Nacional (1941), Fábrica Nacional de Motores (1942), Companhia Vale do Rio Doce (1942), BNDE (1952), Petrobrás (1953), resistindo ao componente imperialista. A partir de JK, essa forma de integrar o Estado mudou, porque se utilizou do capitalismo monopolista nacional para cumprir as finalidades da exploração imperialista.A mudança de eixo no comando interno da economia foi, assim, reflexo do "desenvolvimentismo" de Kubitschek composto por forças formadas principalmente pelos setores ligados ao imperialismo, com bases políticas no latifúndio, diferentemente do segundo governo Vargas, que privilegiava a ação estatal em consonância com um projeto de revolução tipicamente burguesa. A internacionalização produtiva da economia como pressuposto fundamental do Plano de Metas significou uma "opção deliberada" ao imperialismo, uma vez que o Plano de Metas se assentou fundamentalmente na entrada maciça de investimentos estrangeiros, fortemente subsidiados pelo Estado ${ }^{11}$.

11 "No desenvolvimento do capitalismo brasileiro, até a metade da década dos cinquenta, ficara marcado o seu crescimento quantitativo, em extensão, pelo alastramento das 
Não foi por outro motivo que esse desenvolvimento capitalista e suas contradições que desaguavam em uma assimilação mais intensa do imperialismo na vida social brasileira, iriam radicalizar a luta de classes exacerbando os conflitos que encaminhavam o desfecho para a revolução democrática burguesa. Desse modo, entramos no segundo ângulo de análise de Sodré sobre a dinâmica das relações sociais de produção na sociedade brasileira que inseriam revolução e contrarrevolução nos quadros da crise mundial do imperialismo.

Sodré (1978b) identificou na implantação da indústria pesada, e, consequentemente, na elevação do grau de incorporação do imperialismo, por meio das empresas multinacionais, no mercado interno brasileiro, bem como na radicalização dos conflitos no campo e nas cidades, uma dinâmica contraditória das forças sociais em jogo que transitava para uma relação antagônica, portanto, de posições inconciliáveis ${ }^{12}$. Os termos da polarização se davam entre classes e suas frações que se alinhavam ao imperialismo vis-à-vis o nacionalismo. O problema brasileiro refletia a etapa imperialista na qual sua restauração no pós-Segunda Guerra enfrentava um bloqueio da dinâmica de transformação das economias coloniais em nacionais. O próprio capital internacional nesse momento havia modificado seu papel ao mesclar-se com elementos nacionais, subordinando o Estado brasileiro e as burguesias nativas ao seu ímpeto de conquista. Em correspondência, os grandes proprietários rurais exportadores, setores industriais dependentes de filiais estrangeiras, comerciantes que ganhavam com os importados, constituíam a ampla base interna para sua valorização. Opostamente, as indústrias voltadas ao mercado

relações capitalistas, inclusive a faixas rurais, pela integração de camadas da população à economia de mercado; a partir de então, começava nova etapa, de crescimento qualitativo, em profundidade, com a acumulação tendo atingido certo nível que permitia passar a nova escala, com o mercado tendo sido ampliado ao máximo, nas limitações que, precisamente, vão levar à crise do sistema. Porque a primeira fase esgotara as possibilidades de crescimento compatíveis com tais limitações: a do latifúndio, estreitando o mercado interno, disputado ainda pelo imperialismo; as deste, fechando o mercado externo, situando-o como inacessível. [...] O que se processa, nessa base de transição, é a criação de laços de estreita dependência, que subordinam a estrutura econômica brasileira aos interesses externos." (Sodré, 1975, p. 88-89) Sobre as descontinuidades entre o período Vargas e Kubitschek, ver Campos $(2003,2015)$.

12 Interpretação parecida a outros autores que analisaram o fenômeno da Revolução Brasileira, como o caso de Caio Prado Jr. (1987) e Florestan Fernandes (2006). 
interno que sofriam a concorrência assimétrica do capital internacional, pequenos produtores rurais em disputa com o latifúndio, comerciantes que colocavam produtos nacionais contra a oferta de similares importados e as classes trabalhadoras em geral constituíam em seu conjunto a luta pelo elemento nacional e democrático capaz de destruir o que restava de colonial na estrutura produtiva brasileira. Nosso autor expunha assim os contornos básicos da Revolução Brasileira em curso, cujo sujeito histórico seria o "povo" (Sodré, 1962).

Ao analisarmos diacronicamente, retomando o item anterior, a constituição do povo brasileiro em Sodré seria derivada de um processo não linear e eivado de conflitos, avanços e retrocessos. Sodré (1976) classificava em três períodos decisivos o surgimento e ascensão dessa categoria histórica. Durante o primeiro ciclo, o da Independência e Abolição (1822-1888), as forças sociais em jogo estavam dispostas em pesos muito desiguais como visto no item anterior, sendo a classe dominante colonial persistente e acompanhada de vácuos econômicos que mantinham espessos laços de servidão. Não obstante, a decadência da economia mineira criou fissuras na estrutura de poder colonial que se definia nesse período pela consolidação de uma classe intermediária entre os senhores e os escravos ou servos. Uma camada média que começava a lutar pela autonomia política.Assim, surgia o povo brasileiro, que, mesmo sofrendo a repressão da classe dominante, acumulava consciência e participava de momentos-chave no século XIX com o abolicionismo.

No segundo ciclo, o da República (1889-1929), as forças arcaicas permaneciam se impondo por uma população submetida a relações servis nas zonas rurais, pela política econômica ortodoxa em defesa do café e financiada pelo imperialismo e por uma classe de grandes capitalistas do café que negavam a pequena burguesia. Por sua vez, a pequena burguesia se fortalecia em vários flancos, como a do comércio, a do meio militar por ideias positivistas que lastrearam movimentos como o do tenentismo, as vanguardas artísticas que culminariam na Semana de 22, ou determinadas diferenciações tanto no latifúndio, quanto na indústria. Sua organização e seu tensionamento contra o atraso revelavam sua precocidade tanto em relação ao aburguesamento da classe dominante brasileira, quanto da proletarização das classes subalternas.

A junção de diferentes camadas da sociedade brasileira em nome da questão nacional sob vanguarda democrática da pequena burguesia 
permitiu que parisse o terceiro ciclo, o da Revolução (1930-1964), de um lado, a burguesia nacional e outras camadas do povo brasileiro, de outro, as burguesias e outras frações de classe associadas ao imperialismo e ao latifúndio. Mas afinal quem era a burguesia nacional para Sodré? Quantitativamente, quanto maior sua fração menor era sua adesão à causa da Revolução Brasileira; qualitativamente, ela era contra o imperialismo e as forças autoritárias que se vinculam ao comércio e ao latifúndio. Quem era o povo nesse ciclo? Partes de todas as frações da burguesia (alta, média e pequena) que se definiam em posições contrárias à associação com o imperialismo, e o proletariado, o semiproletariado e os camponeses, que agora estavam em crescente organização política.

O acirramento da luta de classes nos anos que antecediam o Golpe de 1964 moldaria sincronicamente as partes que integravam a totalidade da revolução democrática burguesa para Sodré (1978b).A questão nacional seria caracterizada por diferentes estágios para o desenvolvimento capitalista em países de origem colonial como o Brasil, sendo a burguesia nacional nessa quadra um elemento decisivo do povo brasileiro como sujeito histórico da transformação social ${ }^{13}$. A agenda de reformas se reorganizaria pelas seguintes questões:

1) a ruptura com o imperialismo nacionalizando as empresas estrangeiras e destruindo seus meios materiais que financiavam atividades políticas, econômicas e de propaganda internos para a contrarrevolução;

2) a superação do latifúndio integrando-o na economia de mercado via reforma agrária que concederia aos camponeses propriedade

13 “O processo de Revolução Brasileira, em que a burguesia nacional tem um lugar e que, no seu desenvolvimento, fracionará provavelmente essa classe, poderá, finalmente, resolver-se pela forma violenta ou pela forma não violenta, dependendo das condições que se apresentem na sucessividade de seus episódios. De qualquer forma, ele segue o seu desenvolvimento, já estamos em seu curso, não se trata do futuro, mas do presente, trata-se de processo objetivo e natural, e levará, fatalmente, ao problema fundamental, que é o problema do poder. Dependerá muito da burguesia a forma pacífica ou não pacífica do curso revolucionário, que é a essência das transformações em processo. Porque não é o proletariado, nem é o campesinato, que está com a sua sorte de classe em jogo. É a burguesia que está decidindo seu próprio destino." (Sodré, 1967, p. 378-379) 
privada da terra e condições creditícias e políticas para a comercialização de sua produção agrícola;

3) a alavancagem de um genuíno desenvolvimento nacional por meio da ampliação e renovação das técnicas nacionais, da transformação das fontes de energia, das alterações no comércio exterior, do desenvolvimento da produção industrial, da preponderância do mercado interno, da ampliação do mercado de trabalho, do desenvolvimento do setor estatal e do desligamento de compromissos militares externos.

O que se observa com essas proposições é que, ao dilatar os canais democráticos para as classes mais baixas, assim como enfrentar os nexos de dependência, rompia-se para Sodré com as forças externas e internas e buscava-se a substituição da classe dominante não por outra classe minoritária, mas pelo povo. Embora essa interpretação histórica de Sodré estivesse hermeticamente ajustada à sua fundamentação teórica marxista, concatenada, por via de regra, com suas premissas para formação econômica brasileira, a própria história surpreendeu-o em 1ํabril de 1964. De igual maneira, toda essa agenda democrático-burguesa de reformas radicais sucumbiu à contrarrevolução sob uma ditadura de longa duração. O recuo interpretativo de nosso autor para justificar o malogro da Revolução Brasileira e os enigmas de seu sujeito histórico, o povo, assinalavam, por um lado, os próprios limites de sua abordagem sobre a manifestação do imperialismo numa economia de origem colonial como a brasileira; por outro, sua leitura era equivocada sobre o ethos da burguesia brasileira, que pareceria não se constituir nem como nacionalista e tampouco preocupada com a ampliação das forças democráticas no país.

Nas edições posteriores de Introdução à Revolução Brasileira de 1958 e outras obras, Sodré (1978b, 1975, 1997b) tentou explicar o Golpe de 1964 como resultado da articulação de uma ultradireita composta pelo imperialismo e pelas burguesias não nacionalistas e subordinadas; por via de regra, classes dominantes não classificadas como povo, que promoveram uma "intervenção cirúrgica" para anestesiar e destruir o componente revolucionário das reformas. De outro lado, um "esquerdismo" que não aceitava a ausência dos componentes socialistas das reformas, e com isso se opunha à luta pela revolução democrática burguesa. Também responsabilizava os militares brasileiros, os quais sempre tiveram um 
comportamento vacilante entre a "questão nacional-legalista" e o “imperialismo-golpista”. Na verdade, os militares para Sodré (1997b) sempre foram facilmente manipulados em virtude da nossa "revolução burguesa tardia", de modo a aglutinar ao seu redor forças reacionárias de outras classes e do próprio imperialismo. Sobre a burguesia nacional, Sodré (1975) admitia que sobrestimou seu componente democrático, mas continuava a acreditar que seu elemento nacional fosse majoritário, exemplificando iniciativas de estatização da ditadura militar. Nem mesmo diante da "farsa do neoliberalismo", e de toda a transnacionalização da economia internacional que ele denominava de "novo imperialismo" a partir da década de 1970 , Sodré $(1975,1995)$ abandonou a crença que pudesse haver um reconhecimento por parte da burguesia brasileira da questão nacional de modo a desencadear novamente a revolução democrática burguesa.

Sem deixar de admitir na obra de Sodré um inegável avanço na análise entre a apreensão do modo de produção capitalista, dinâmicas específicas do imperialismo em determinados contextos de luta de classes e espaços nacionais periféricos, a utilização do método e sua aplicação sem as devidas depurações fazem com que nosso autor, ao priorizar a ortodoxia da análise marxista, se coloque sempre em atraso às vicissitudes da formação histórica brasileira. Em todo momento há uma pretensão de reconstruir a história econômica brasileira respeitando uma suposta pureza das categorias analíticas de Marx, principalmente as que dizem respeito ao desenvolvimento das forças produtivas e das relações sociais de produção seguindo à risca referências soviéticas, como as de Afanasiev (1968) e Konstantinov (1959). Dessa maneira, a reconstrução histórica e a categorização parecem andar sempre justapostas, sem grandes mediações e com a necessidade de atualizar a todo momento a sua interpretação,já que na maior parte das vezes a história surpreende a aplicação teórica de Sodré.Tal problema foi percebido por Netto (2011) como um descompasso entre as concepções teórico-metodológicas e a narrativa histórica em função de generalizações com insuficiências empíricas.

Assim, o caso marcante desse problema na obra de Sodré aparece na formulação da Revolução Brasileira superestimando a suposta "burguesia nacional" e o componente democrático das Forças Armadas, ao mesmo tempo em que subestima as implicações econômicas, sociopolíticas e ideológicas já alcançadas pela assimilação acelerada do imperialismo 
tanto na burguesia brasileira, quanto no próprio Exército. Em fase embrionária, o nacionalismo seria mais um elemento em construção nas forças populares não burguesas, do que na própria burguesia brasileira. Ao ter como perspectiva o Exército, e sua ala nacionalista e legalista geralmente de baixa patente, Sodré acabou por transpor uma demasiada dosagem de substância nacional e democrática às classes burguesas, deixando seu instrumental analítico teórico lento em relação às rápidas mudanças no processo histórico que dinamizavam a dominação imperialista e sua internalização precoce na formação da burguesia brasileira.

Foi justamente por esse flanco que Caio Prado Jr. (1987) lançou severas críticas no âmbito do PCB, tanto a suposição de "origem feudal" que marcava o latifúndio exigindo reforma agrária para sua superação, quanto a existência de uma "burguesia nacional" que tivesse identidade popular capaz de levar adiante o programa de revolução democrática burguesa contra o imperialismo. Diferente de Sodré, para Prado Jr. a herança mercantil da formação histórica brasileira trazia consigo um espaço rural integrado à lógica de exploração capitalista mercantil voltada para as exportações, assim como uma burguesia integrada tanto à especialização agrícola, quanto às vantagens de associação subordinada ao imperialismo; participantes, pois, de um portfólio de negócios que lhes impedia creditar determinado nacionalismo e pendor democrático.

$\mathrm{Na}$ mesma direção dessa crítica, Florestan Fernandes (2006), que dedicou ampla investigação sobre a correlação de forças políticas que definia o padrão de luta de classes na revolução burguesa do Brasil, revelou em sua análise o caráter compósito da burguesia brasileira, que, além de ser herdeira do passado mercantil de dominação, encarnava a vanguarda na contrarrevolução orientada pelo capitalismo monopolista perante os desdobramentos da revolução bolchevique. O Golpe de 1964 para Fernandes não seria apenas a realização de uma lógica imperialista exógena que se impunha contra as reformas radicais internas. $\mathrm{Na}$ verdade, essa era a própria conclusão da revolução burguesa possível na periferia de origem colonial, em que a burguesia brasileira, como escudeira endógena do "imperialismo total", era protagonista na contrarrevolução defensiva ao perigo socialista, de modo a sacramentar políticas antipopulares e antidemocráticas, perpetuando o capitalismo dependente e a segregação social no país. 


\section{Conclusão}

O presente trabalho pretendeu problematizar a questão nacional na obra de Nelson Werneck Sodré. Para tanto, procurou discernir o fio condutor da formação histórica do Brasil como um lento processo histórico de diferenciação e de formação nacional. Em cada momento, o processo de formação avança sob os condicionamentos estruturais do movimento de constituição e desenvolvimento do capitalismo mundial, em suas diversas etapas. Mas, contraditoriamente, em cada momento o avanço da formação põe em causa a emancipação de caráter nacional em relação a esses mesmos condicionamentos. Noutros termos, o desenvolvimento do capitalismo, de sua formação à sua maturação, sempre um processo desigual e combinado, condiciona as possibilidades e os limites do polo periférico, e em cada ruptura repõe, em novas bases, a dominação colonial ou neocolonial. Assim foi na passagem da etapa da economia colonial à economia dependente, quando a superação do capital mercantil pelas formas mais plenamente desenvolvidas do capital correspondeu à substituição do "antigo sistema colonial" pela hegemonia britânica; ou, na consolidação da economia dependente, quando a maturação do desenvolvimento capitalista correspondeu ao fenômeno do imperialismo. No entanto, para Sodré, no curso da formação, a sociedade nacional vai se diferenciando e se consolidando em progressiva tensão com o quadro da dominação externa.

O ponto crítico desse movimento secular será o século XX, quando, na formação brasileira, os primeiros desenvolvimentos de forças produtivas e relações de produção tipicamente capitalistas são coetâneos da crise e da fratura da ordem imperialista, das guerras mundiais e da Revolução Russa. Esse novo quadro marca o caráter daí em diante revolucionário da consumação da formação nacional no Brasil. Não por acaso, essa mesma quadra vê eclodir, sob os escombros dos velhos impérios coloniais, um conjunto de lutas de caráter nacional na periferia do capitalismo com desfechos revolucionários. Nesse entroncamento entre a consumação da formação nacional e a crise disruptiva do capitalismo mundial, Sodré procura equacionar as tensões entre o universal e o particular para, enfim, captar o sentido da Revolução Brasileira - e seu respectivo sujeito. A luta em torno do comando e da direção do processo de desenvolvimento capitalista, da industrialização, e seus reflexos na 
superestrutura - que culminam no Golpe de 1964 - constituem o momento crítico.

$\mathrm{Na}$ leitura ora proposta, atestamos os percalços, nessa obra, para se coadunar a dimensão conceitual e a narrativa histórica - e, portanto, os limites para a apreensão do sentido das transformações então em curso na sociedade brasileira. Se tal descolamento entre o conceito e a história deve ser observado na tensão entre o sentido da colonização e a caracterização dos modos de produção coloniais - tema não tratado no presente trabalho -, também deverá ser na caracterização da Revolução Brasileira e, em particular, do estatuto da burguesia, então qualificada como "nacional". O movimento da obra de Sodré, constantemente reavaliada pelo próprio autor, revela a necessidade permanente de reencontrar esses elos perdidos da história em curso. Por certo, em suas revisões, Sodré não abriu mão da tese em torno da revolução burguesa no Brasil de caráter nacional e democrático, o que supunha o caráter também nacional e democrático de nossa burguesia ou, pelo menos, de parte dela. De nossa parte, entendemos que o Golpe de 1964 e seus desdobramentos revelam que o passado colonial havia forjado uma burguesia consonante com a preservação da estrutura do campo e com a subordinação ao imperialismo. O golpe não era a ruptura externa de uma revolução burguesa democrática em curso, mas seu próprio desfecho, nas condições históricas em que se realizou.

\section{Referências bibliográficas}

AFANASIEV,V. Fundamentos da filosofia. Rio de Janeiro: Civilização Brasileira, 1968.

CAMPOS, F.A. Estratégias de desenvolvimento nacional: o papel do capital estrangeiro entre o segundo governo Vargas e o governo Castelo Branco (1951-1966). Campinas: Instituto de Economia, Universidade Estadual de Campinas, 2003 (Dissertação de Mestrado).

CAMPOS, F.A. Multinational firms and the regulatory framework in Brazil (1951-1967). Apuntes, 42 (76), p. 137-172, 2015.

CAMPOS, F.A. Introdução à formação econômica do Brasil: herança colonial, industrialização dependente e reversão neocolonial. Marília: Lutas Anticapital, 2018.

CUNHA, P. R. Um olhar à esquerda: a utopia tenentista na construção do pensamento marxista de Nelson Werneck Sodré. Rio de Janeiro: Revan, 2002.

CUNHA, P. R; CABRAL, F. (org.). Nelson Werneck Sodré. Entre o saber e a pena. São Paulo: UNESP, 2006. 
FERNANDES, F. A revolução burguesa no Brasil: ensaio de interpretação sociológica. 5. ed. São Paulo: Global, 2006.

FURTADO, C. Formação econômica do Brasil. 13. ed. São Paulo: Nacional, 1975.

HOBSBAWM, E. J. Nações e nacionalismo desde 1780: programa, mito e realidade. 2. ed. Rio de janeiro: Paz e Terra, 1990.

KONSTANTINOV, F.V. Los fundamentos de la filosofía marxista. México: Grijalbo, 1959. LENIN,V. O imperialismo: fase superior do capitalismo. São Paulo: Global, 1979.

LENIN, V. Do direito de autodeterminação nacional. In: PINSKY, J. (org.). Questão nacional e marxismo. São Paulo: Brasiliense, 1980.

LÖWY, M. Nacionalismos e internacionalismos: da época de Marx até os nossos dias. São Paulo: Xamã, 2000.

NETTO, J. P. Nelson Werneck Sodré: o general da história e da cultura. São Paulo: Expressão Popular, 2011.

NIKITIN, P. Fundamentos de economia política. Rio de Janeiro: Civilização Brasileira, 1967.

NOVAIS, F. A. Portugal e Brasil na crise do antigo sistema colonial (1777-1808). 6. ed. São Paulo: HUCITEC, 1995.

OLIVEIRA FILHO,V. R. A participação de Werneck Sodré no debate nacionalista da década de 1950. In: CUNHA, P. R.; CABRAL, F. (org.). Nelson Werneck Sodré. Entre o saber e a pena. São Paulo: UNESP, 2006.

PINSKY, J. (org.). Questão nacional e marxismo. São Paulo: Brasiliense, 1980.

PRADO JR., C. A Revolução Brasileira. 7. ed. São Paulo: Brasiliense, 1987.

PRADO JR., C. Formação do Brasil contemporâneo. São Paulo: Brasiliense/Publifolha, 2000.

ROSENTAL, M. Les problèms de la dilectique dans Le capital de Marx. Paris: Sociales, 1959.

SEGATO, J. A. A Revolução Brasileira. In: CUNHA, P. R.; CABRAL, F. (org.). Nelson Werneck Sodré. Entre o saber e a pena. São Paulo: UNESP, 2006.

SILVA, M. (org.). Nelson Werneck Sodré na historiografia brasileira. Bauru/São Paulo: EDUSC/FAPESP, 2001.

SILVA, M. (org.). Dicionário crítico Nelson Werneck Sodré. Rio de Janeiro: UFRJ, 2008.

SODRÉ, N. W. Panorama do segundo Império. Rio de Janeiro: Companhia Editora Nacional, 1939.

SODRÉ, N.W. Quem é o povo no Brasil?. Rio de Janeiro: Civilização Brasileira, 1962.

SODRÉ, N. W. História da burguesia brasileira. 2. ed. Rio de Janeiro: Civilização Brasileira, 1967.

SODRÉ, N.W. Fundamentos de economia marxista. Rio de Janeiro: Civilização Brasileira, 1968a.

SODRÉ, N.W. Fundamentos do materialismo histórico. Rio de Janeiro: Civilização Brasileira, 1968b.

SODRÉ, N. W. Brasil: radiografia de um modelo. Petrópolis:Vozes, 1975.

SODRÉ, N. W. Formação histórica do Brasil. 9. ed. Rio de Janeiro: Civilização Brasileira, 1976. 
SODRÉ, N. W. As razões da Independência. 3. ed. Rio de Janeiro: Civilização Brasileira, 1978a.

SODRÉ, N. W. Introdução à Revolução Brasileira. 4. ed. Rio de Janeiro: Rio de Janeiro: Civilização Brasileira, 1978 b.

SODRÉ, N.W. A farsa do neoliberalismo. Rio de Janeiro: Graphia, 1995.

SODRÉ, N.W. Capitalismo e revolução burguesa no Brasil. 2. ed. Rio de Janeiro: Graphia, 1997a.

SODRÉ, N. W. Era o golpe de 64 inevitável?. In:TOLEDO, C. N. (org.). 1964: visões críticas do golpe - democracia e reformas no populismo. Campinas: UNICAMP, 1997b.

TOLEDO, C. N. Nacionalismo e ISEB em Nelson Werneck Sodré. In: SILVA, M. (org.). Nelson Werneck Sodré na historiografia brasileira. Bauru/São Paulo: EDUSC/FAPESP, 2001.

VIEIRA, C.A. C. Interpretações da colônia: leitura do debate brasileiro de inspiração marxista. Campinas: Instituto de Economia, Universidade Estadual de Campinas, 2004 (Dissertação de Mestrado).

VIEIRA, C.A.C. Interpretações da colônia: leitura das contribuições de Nelson Werneck Sodré e Alberto Passos Guimarães. História Econômica \& História de Empresas, v. XI, p. 29-61, 2008.

VIEIRA, C. A. C. Antigo Regime e transição: breve estudo em torno do capital mercantil e do absolutismo. Campinas: Instituto de Economia, Universidade Estadual de Campinas, 2012 (Tese de Doutorado). 